\title{
Assessment of eating behaviour in obese children of Bangor city
}

\author{
Attallah O. Qasem \\ Biomedical Research Unit, Sulaimani Polytechnic University, Sulaimani, Kurdistan Region, Iraq. \\ Corresponding Author: atta.kasem@spu.edu.iq
}

Received| November 2, 2015

Accepted|January 04, 2016

\begin{abstract}
Obesity is a major health problem for people living in the UK, and it currently affects many children. The objectives of this study is to assess the psychometric measures of eating behaviour associated with obesity in primary school-aged children in the city of Bangor (North Wales, UK). Across-sectional survey of children's eating behaviours and their relationship to obesity was done in four primary schools in the city of Bangor (North Wales, UK).

The study utilized the method of cross-sectional survey of Wales's children's eating behaviour in association with obesity using two groups of children aged 7-8 years and 10-11 years through four junior schools in Bangor. It was assessed using the Child Eating Behaviour Questionnaire (CEBQ) and body composition was estimated using BMIs. Total of 153 children 81 were boys and 72 were girls. The statistical analysis used is based on multiple regression analysis with the dependent or predicted variable being BMI and the independent or predictor variables being food responsiveness, emotional under eating and exercise.

It was found that exercise was significant at $p$ value $<0.042$ and negatively associated with BMI, which means that there is a significant difference between exercise and BMI. Two behavioural characteristics derived from the CEBQ which are food responsiveness and emotional under-eating. This is statistically significant at $p$ value $<0.01$ and positively associated with BMI, show that increase food responsiveness and emotional under-eating is different with increases of BMI.
\end{abstract}

The psychometric measures of children's eating styles obtained from CEBQ showed that exercise change as above, with BMI; that is children who were rated as having more exercise were more likely to have a lower BMI.

Key words: BMI, exercise, appetite, satiety, food responsiveness, under-eating.

\section{Introduction}

Obesity is now known as a worldwide epidemic condition (WHO, 2003) and has been predicted to become the largest drain on health service resources in the UK in the near future. Nonetheless, there are 14 million overweight school-age children in the European Union (EU), of whom three million are obese (International Obesity Taskforce, 2004a). The number of overweight children in the EU is rising by around 400,000 per annum, of whom 85,000 are obese (International Obesity Taskforce, 2004b). 
In the UK, there are approximately one million obese individuals who are less than 16 years of age (Educari, 2004). Butriss (1995) showed a similar picture through a survey in the UK, with $75 \%$ of children aged 10-11 exceeding the recommended target level for percentage of energy derived from fat. Therefore, Wardle et al (2005) and Currie et al. (1997) have reported comparable results. Also, the Health Survey for England (HSE) illustrated the prevalence of obesity doubled between 1984 and 1994 among 4- 12 year olds children in England, rising from $0.6 \%$ to $1.7 \%$ in boys and from 1.3 to $2.6 \%$ in girls. In 2004; the Health Survey for England illustrated an overall increase in obesity amongst the number of children aged 210 who are obese from $9.9 \%$ in 1995 to $13.4 \%$ in 2004 (House of Commons Committee of Public Accounts, 2007).

A previous survey by Cameron and colleague (2006) showed that the consequences of childhood obesity in developed countries have extended into the most widespread nutritional disease.

In 2006, the National Institute for Health and Clinical Excellence NICE indicated morbidities in children and adolescents that include dyslipidaemia, hyperinsulinaemia, hypertension, psychosocial dysfunction, type 2 diabetes and asthma (NICE, 2006).

Many studies have presented evidence indicating that dietary habits acquired in childhood often continue during adulthood (e.g. Kelder, et al., 1994; Nicklas, 1995; Steptoe et al., 1995). As the severity of childhood obesity increases the risk of obesity throughout the growing age of the child, the persistence of childhood obesity into adulthood is the most significant concern (NICE,
2006).The risk factor of a number of chronic diseases in adult life such as heart disease, osteoarthritis, and some cancers are linked to childhood obesity (British Medical Association, 2005). Likewise, psychological problems such as rejection, shame, depression and stress are also more likely to occur in obese children than nonobese children (Reilly, 2003).

The UK Government has reacted to decreasing childhood obesity with a Public Service Agreement goal to stop increase in obesity among children below the age of 11 by 2010 (Department of Health, 2007a).

The present measure is aimed at primary school children from the reception year (ages 4-5 years) and (ages 10-11 years) by Primary Care Trusts (PCTs) (Department of Health, 2007b).

The Welsh Health Survey shows that the number of children under 16 who are classed as obese jumped by $3 \%$ in 2009 . Recently one out of five children in Wales is obese (Brindley and Mail, 2010). This takes childhood obesity in Wales to near the peak suggested by the International Childhood Obesity Association (Brindley and Mail, 2010). Furthermore, Leigh (2010) shows that the proportion of children aged between ( 2 and 15) classed as obese increased to $19 \%$ in 2009 from $16 \%$ in 2008 , which has led to the present situation where Wales has become the country with the highest childhood obesity rates in the world.

There is no clear explanation of the primary cause of overweight and obesity in children and adolescents, although dietary and/or physical activity patterns are likely to be important factors 
to obesity (Janssen et al., 2005). Thus, the relationships between various dietary and physical activity and paediatric weight need to be determined (Janssen,et al., 2005).Wardle 2001suggest that obese children are behaves differently from non-obese children they prefer different types of food, eat for different reasons, and eat with a different style (Wardle, et al., 2001).

\section{Materials and Methods}

The cross-sectional survey was used in four primary schools of Wales's children's eating behaviour and their association with obesity using two groups of children aged 7-8 years and 10-11 years through four junior schools in Bangor. Child Eating Behaviour Questionnaire (CEBQ) been used and also body composition was estimated using BMIs. The study information was gained by the parents on behalf of their children. In total 153 parents gave their consent and information on 153 children was obtained of whom 81 were boys and 72 were girls. The statistical analysis used is based on multiple regression analysis with BMI as the dependent or predicted variable and food responsiveness, emotional under eating and exercise as the independent or predictor variables.

\section{Participants}

153 children's parents were recruited in this study and their children were classified in two age groups, 7-8 years and 10-11 years old, from four junior schools in Bangor (North Wales, UK). The children were approached by the staff at the school and asked them to take the questionnaires to their parents for their approval to participate in the survey. Seventy four of the children were in the first age group and 79 in the second age group, and their gender was 81 boys and 72 girls.

\section{Measures}

Two measures were used: the Children's Eating Behaviour Questionnaire (CEBQ) (Wardle, et al., 2001a) and the child's BMI. The CEBQ consists of 35 items and another item added by the researcher to make 36 items divided into seven subscales. The questions are answered by ticking one of the following five options (never, rarely, sometimes, often, always, numbered 0 to 4 respectively). The questions provide information on seven behavioural components (satiety/slowness in eating, fussiness, food responsiveness, enjoyment of food, drinking, emotional under-eating and over-eating). And a question on exercise was added to the questionnaire. Therefore, questions were probably ordered according to components, and some are "reversed" i.e., they go in the opposite direction from those of other measures of the same component. See Appendix A, B, for the specific components and the questions that be relevant to them.

\section{Data analysis}

SPSS version 18 was used to achieve data management and computations of descriptive and inferential statistics. In statistical testing a $P$ value of 0.05 or below was considered to indicate statistical significance.

The main analysis was in two stages, by using multiple regressions. Multiple regressions with entry were used to find out the relationship between several independent or predictor variables and a dependent or criterion variable. 
The initial regression model is thus shown in Equation 2.

\begin{tabular}{|l|l|}
\hline BMI $=\beta_{0}+\beta_{1}$ satiety/slowness etc + & \\
$\beta_{2}$ fussiness $+\beta_{3}$ food responsiveness + & \\
$\beta_{4}$ enjoyment of food $+\beta_{5}$ drinking $_{i}+$ & (Eq.2) \\
$\beta_{6}$ emotional under-eating + & \\
$\beta_{7}$ emotional over-eating $+\beta_{8}$ exercise & \\
$+\beta_{9}$ gender $+\beta_{10}$ two age groups $+\varepsilon$ & \\
\hline
\end{tabular}

\section{Results}

About 310 children took the questionnaires for their parents' consent and 50\% returned the questionnaires. This means that 153 pupil's parent who took part, of whom 81 were males and 72 were females. The Means of heights of the children $\mathrm{b} 12.17 \mathrm{~cm} 2$ to $13.23 \mathrm{~cm}$, and their weights ranged from $12.09 \mathrm{~kg}$ to $30.23 \mathrm{~kg}$ as indicated in (Table 1).

Table 1: Shows the biographical data.

\begin{tabular}{|c|c|c|c|c|}
\hline $\mathbf{N}$ & Boys & Girls & $\begin{array}{c}\text { Means of } \\
\text { Height }\left(\mathbf{c m}^{\mathbf{2}}\right) \\
\text { Ranged }\end{array}$ & $\begin{array}{c}\text { Means of } \\
\text { Weight }(\mathbf{k g}) \\
\text { Ranged }\end{array}$ \\
\hline 153 & 81 & 72 & $12.1718-$ & $12.0900-$ \\
& & & $30.2338 \mathrm{~cm}$ & $30.2338 \mathrm{~kg}$ \\
\hline
\end{tabular}

Table 2 shows that the F-ratio $=3.597 . \mathrm{F}$ is highly significant at 0.001 levels. Therefore the linear regression model as a whole is highly significant, which indicates that the combined effect of the independent variables is associated with the dependent variable BMI is highly significant as revealed in (Table 2). However, it was found that exercise was significant at 5\% and negatively associated with BMI with coefficient $(-0.471)$. This indicate that when exercise increases the BMI decease. Two behavioural characteristics derived from the CEBQ, food responsiveness and emotional under-eating were significant at $1 \%$ and positively associated with BMI, meaning that when food responsiveness and emotional undereating increases so does BMI as shown in (Table $3)$.

The rest of the independent variables in the model appear to have no significant effects on BMI like and some have positive and others have negative coefficients like. When we use Stepwise method instead of Enter method in order to know relationship between the dependent variable BMI and the independent variables we obtain only three independent variables are selected, as having significant effects on BMI, these are food responsiveness, emotional under eating and exercise, as shown in (Table 4)

Table 2: Shows ANOVA ${ }^{a}$ for model 1.

\begin{tabular}{|c|c|c|c|c|c|}
\hline Model & Sum of Squares & Df & Mean Square & F & Sig. \\
\hline Regression & 140.115 & 3 & 46.705 & 9.862 & $0.000^{\mathrm{b}}$ \\
Residual & 705.655 & 149 & 4.736 & & \\
Total & 845.770 & 152 & & & \\
\hline
\end{tabular}

a) Dependent Variable: BMI kg/m2.

b) Predictors: (Constant), Exercise, 7-8=1,10-11=2, Food responsiveness, male 1, female 2, Emotional undereating, Enjoyment of food, satiety/slowness, Desire to drink, Fussiness, Emotional over-eating 
Table 3: Shows ANOVA ${ }^{a}$ for model 1.

\begin{tabular}{|c|c|c|c|c|c|}
\hline Model & $\begin{array}{c}\text { Sum of } \\
\text { Squares }\end{array}$ & df & Mean Square & F & Sig. \\
\hline 1 & 170.949 & 10 & 17.095 & 3.597 & $0.000^{\mathrm{b}}$ \\
Regression & 674.821 & 142 & 4.752 & & \\
Residual & 845.770 & 152 & & & \\
\hline
\end{tabular}

a) Dependent Variable: $\mathrm{kg} / \mathrm{m} 2$.

b) Predictors: (Constant), Food responsiveness, Emotional under-eating, Exercise

The stepwise regression Criteria used was compared with the corresponding results of the Probability-of F- to enter $\leq 0.05$ and Probability F- full model; the effects of these 3 independent to- remove $\geq 0.1$. Therefore, 3 independent variables on BMI are significant with positive and variables in the model are more significant negative coefficients.

Table 4: Shows coefficients for model 1.

\begin{tabular}{|c|c|c|c|c|c|}
\hline \multirow{2}{*}{ Model } & \multicolumn{3}{|c|}{ Coefficients } \\
& \multicolumn{2}{|c|}{ Unstandardized Coefficients } & $\begin{array}{c}\text { Standardized } \\
\text { Coefficients }\end{array}$ & \multirow{2}{*}{ T } & Sig. \\
\cline { 2 - 5 } & B & Std. Error & Beta & 13.690 & 0.000 \\
Food responsiveness & 17.395 & 1.271 & 243 & 3.217 & 0.002 \\
Emotional under-eating & 0.912 & 0.284 & 0.209 & 2.676 & 0.008 \\
Exercise & 0.471 & 0.299 & 0.160 & 2.048 & 0.042 \\
\hline
\end{tabular}

a) Dependent Variable: BMI kg/m2

\section{Discussion}

During the present study, the relations between BMI and the independent variables were analysed using multiple regression methods (Enter and Stepwise). As a whole is highly significant, where the p-value is less than 0.001. This means that the combined effect of independent variables on BMI is highly significant. In the present study, the effects of the ten independent variables on BMI show that only 3 variables, food responsiveness, emotional under eating and exercise, have significant or near significant effects on BMI. On the other hand, Webber et al. (2009) found that six independent variables had significant effects on BMI including food responsiveness. Noticeably, according to the current study results, there appears to be a significant relationship between food responsiveness, which means that when food responsiveness increases, then BMI also increases and conversely. Technically, it means that people with higher amounts of food responsiveness also tend to have higher BMIs. 
This finding supports Webber et al. (2009) result, which showed that there is a positive relationship between food responsiveness and obesity. Epstein et al. (2007) showed that obese children were prepared to try comparatively harder to obtain more food than normal-weight children. Recently, another result showed that eating rich food at age 7 predicted weight gain prospectively over time (Hill, et al., 2009). Llewellyn, et al. (2008), and Webber et al. (2009) found that the speed of eating, as a potential indicator of obesity was higher in obese children.

When a child is upset the emotional state under eating could be the result of tiredness, anger behaviour which is related to the emotional and physical state of a child. Moreover, through the present study, the researcher found that emotional under-eating increases, and then BMI also increases. Our findings showed that children, who exhibited a higher level of 'emotional undereating', were those who eat less when happy or sad and had a higher BMI. This result has been found in some previous studies.

According to other studies, Braet and Strien, (1997), emotional stress may act as an appetite stimulant for child eating behaviour, and also may lead to risk of developing obesity, which has a direct effect on children. Furthermore, predictors of emotional distress induce changes in eating behaviour are important because emotional disorder may cause overeating (Wadden and Stunkard, 2002, Rand and Stunkard, 1978). Emotional distress and other mood disorders are associated with both increased eating behaviour and obesity. Goodman and Whitaker (2002) found that stressed adolescents were two times more likely to become obese during the one-year follow-up than teens who did not suffer from depression. While in our study we considered only children up to age 11 years. In this study considered the effect of emotional under eating on BMI, which was significant and positive. While in our study we considered only children or lower to age 11 years. In this study even if this is a result of study which considered the effect of emotional status or disorder under eating on BMI, which was significant and positive.

Keith et al. (2006) identified that increase of emotional disorder may be a component of a large range of obesity risk factors and, thus may contribute to the rising occurrence of obesity (Renie and Jebb, 2005, Steptoe et al., 2004). During emotional stress some individuals increase their caloric intake, particularly of saturated fat and carbohydrate (Dallman et al., 2004, YaconoFreeman and Gil, 2004). This is related to emotional under eating discussed in present work.

The eating behaviours disorder children often consist of periods of chronic dieting interrupted by episodic bingeing, and this exposes the children to the risk of weight gain. Polivy and Herman, (1999), Cattanach and Rodin (1988) showed emotional eating disorder and its effects on eating behaviour and obesity, which had a significant positive effect on BMI.

Nevertheless, the present study showed a negative significant relationship between the predictor variable Exercise and BMI and also agrees with present results.

This result agrees with many other studies which have shown that BMI increased significantly when 
physical activity per day decreased (Marty et al., 2006, Patrick et al., 2004).Hill and others (1995) demonstrated that decreasing levels of physical activity would possibly reduce energy spending, and, if not coordinated with reduced food consumption, may produce significant energy imbalance and weight gain. Whereas, Bell et al. (2004) and Hill and Commerfod (1996) identified that a decrease in physical activity would lead to an obvious restriction in the energy expended and may lead to body weight gain. Also other studies, suggest that moderate to high levels of physical activity prevents weight gain and obesity (Di Pietro et al., 2004, French et al., 1994).Therefore, a low level of physical activity is associated with an increased risk of weight gain (Roberts et al., 1988, Griffiths et al,. 1990, Williamson et al., 1993).

\section{Conclusions}

Childhood obesity is an epidemic that continues to dramatically increase resulting in a large percentage of children developing diabetes, and parents cannot recognize when their own children overweight. Although obesity is not yet considered a disease by DSM-IV criteria, recent studies show that the number of obese children has increased medically. We conclude that assessment of exercise, food responsiveness and emotional under eating could be used as indicators of susceptibility to weight gain. Exercise and food responsiveness are in agreement with the results of other researchers however, emotional under eating agrees with some, but not all previous studies. A further study should be undertaken to further detect and quantify the effect of sport and exercise on child's eating behaviour and obesity, and also research necessary to explore the relationship between these factors and BMI in the future.

\section{Acknowledgment}

I am very grateful to many people for making this study possible. I am grateful To Dr. Graham Clarke for this support and advice at every stage of this study and his helpful comment and feedback on numerous drafts of this study. My gratitude also goes to Prof. Dr. Jani Kassab for support and advice on the presentation, the analysis of the data, and for helping to correct my grammar.

\section{References}

Bell, C., Day, D.S., Jones, P.P., Charistou, D.D.; Petitt, D.S., Osterberge, K., Melby, C.L. and Seals, D.R. (2004). High energy flux mediates the tonically augmented-adrenergic support of resting metabolic rate in habitually exercising older adults. J ClinEndocrinolMetab, 89, 3573-3578

Braet, C. and Van-Strien, T. (1997). Assessment of emotional externally induced and restrained eating behaviour in nine to twelve-year-old obese and nonobese children. Behav Res Ther, 35, 863-873.

Brindley, M. and Mail, W. (2010). Recession fuels new rise in child obesity across Wales. Available from: http://www.walesonline.co.uk/news/wales news/2010/05/27/recession-fuels-new-rise-inchild-obesity-across-wales-91466-26531020/ [Accessed 22 August 2010]

Butriss, J. (1995). Nutrition in General Practice, 1st edn, vol. 2. Promoting Health and Preventing Disease. Royal College of General Practitioners, London

British Medical Association, (2005). Preventing Child Obesity. Printed by the BMA publications unit. 174

Cattanach, L. and Rodin, J. (1988). Psychosocial components of the stress process in bulimia. Int $\mathrm{J}$ Eat Disord. 7, $75-88$

Currie, C., Todd, J. and Thompson, C. (1997). Health Behaviours of Scottish School Children: Report 5: Comparisons of National Patterns in 1990 and 1994. Research Unit in Health and Behavioural Change and Health Education Board for Scotland, Edinburgh 
Cameron, N., Norgan, N.G. and Ellison, T.H. (2006). Childhood obesity: contemporary issues. Boca Raton: CRC Press; Taylor \& Francis Group

Dallman, M.F., Lafleur, S.E., Pecoraro, N.C., Gomez, F., Houshyar, H. and Akana, S.F. (2004). Minireview: glucocorticoids: food intake, abdominal obesity, and wealthy nations in 2004. Endocrinology. 145, 2633-2638

Di Pietro, L., Dziura, J. and Blair, S.N. (2004). Estimated change in physical activity levels (PAL) and prediction of 5-year weight change in men: the aerobics centre longitudinal study. Int $\mathrm{J}$ ObesRelatMetabDisord. 28, 1541-1547

Department of Health, (2007a). Spending review PSAs. Available from:

http://www.hm-

treasury.gov.uk/media/70320/sr04_psa_ch3.pdf [Accessed 20 August 2010]

Department of Health, (2007b). Supporting healthy lifestyles: the National Child Measurement Programme Guidance for 2006-07 school years. Available from: http://www.dh.gov.uk/en/Publicationsandstatistics/ Publications/PublicationsPolicyAndGuidance/DH_ 073786 [Accessed 22 August 2010]

Epstein, H. L., Leddy, J.J., Temple, L.J.,and Faith, S.M. (2007). Food Reinforcement and Eating: A Multilevel Analysis. Psychol Bull. 133, (5), 884906

Educari, (2004). Children, young people and health related decisions: a review of the research literature and discussion of the implications for health education of children and young people. Roehampton: University of Surrey

French, S.A., Jeffery, R.W., Forster, J.L., Mcgovern, P.G., Kelder, S.H. and Baxter, J.E. (1994). Predictors of weight change over two years among a population of working adults: the Healthy Worker Project. Int J ObesRelatMetabDisord. 18, 145-154

Goodman, E. and Whitiaker, R.C. (2002). A Prospective Study of the Role of Depression in the Development and Persistence of Adolescent Obesity. Pediatrics. 110 (3), 497-504

Griffiths, M., Payne, P.R., Stunkard, A.J., Rivers, J.P.W. and Cox, M. (1990). Metabolic rate and physical development in children at risk of obesity. Lancet. 336, 76-78

House of Commons Committee of Public Accounts, (2007). Tackling Child Obesity-First Steps. Available from: http://www.publications.parliament.uk/pa/cm2006 07/cmselect/cmpubacc/157/157.pdf. [Accessed 29 September 2010]
Hill, J.O., Melby, C., Johanson, S.L., and Peters, J.C. (1995). Physical activity and energy requirements. Am J Clin Nutr. 62, 1059S-1066S

Hill, C., Saxton, J., Webber, L., Blundell, J. and Wardle, J. (2009). The relative reinforcing value of food predicts weight gain in a longitudinal study of 7-10-y-old children. Am J ClinNutr. 90, 276-281

International Obesity Taskforce, (2004a). Obesity in children and young people, a crisis in public health. Available from: www.iotf.org [Accessed 15 August 2010]

International Obesity Taskforce, 2004b. Estimates, issued at the European congress on obesity. Prague.

NICE, 2006. Obesity: the prevention, identification, assessment and management of overweight and obesity in adults and children. NICE clinical guideline. $43,1-84$

Janssen, I., Katzmarzyk, P.T., Boyce, W.F., Vereecken, C., Mulvihill, C., Roberts, C., Currie, C. and Pickett, W. (2005). Comparison of overweight and obesity prevalence in school-aged youth from 34 countries and their relationships with physical activity and dietary patterns.Obesity. 6, 123-132

Keith, S.W., Redden, D.T. and Katzmarzyk, P.T. (2006). Putative contributors to the secular increase in obesity: exploring the roads less travelled. Int $\mathbf{J}$ Obes. 30, 1585-1594

Kelder, S. H., Perry, C. L., Klepp, K. I. and Lytle, L. L. (1994). Longitudinal Tracking of Adolescent Smoking, Physical-Activity, and Food Choice Behaviours. American Journal of Public Health. 84(7), 1121-1126

Llewellyn, C. H., van Jaarsveld, C. H., Boniface, D., Carnell, S. and Wardle, J. (2008). Eating rate is a heritable phenotype related to weight in children. Am J ClinNutr. 88, 1560-1566

Leigh, R. (2010). Childhood obesity rise in Wales. Available from: http://www.fatfreefitness.co.uk/blog/99/childhoodobesity-rise-in-wales.html [Accessed 22 August 2010]

Marty, K. Wolff, C. and Morgan, I. (2006). Overweight, Diet, Physical Activity, and Hypertension in Low-Income School-Aged Children. Californian Journal of Health Promotion. 4, 47-58

Nicklas, T.A. (1995). Dietary studies of children and young adults (1973-1988): the Bogalusa heart study. American Journal of Medical Science. 310, 101-108

NICE, (2006). Obesity: the prevention, identification, assessment and management of overweight and obesity in adults and children. NICE clinical guideline. (43), 1-84 
Polivy, J. and Herman, C.P. (1999). Distress and eating: why do dieters overeat? Int J Eat Disord. 26, 153164

Patrick, K., Norman, G. J., Calfas, K. J., Sallis, J. F., Zabinski, M. F., Rupp, J., Cella, J. (2004). Diet, physical activity, and sedentary behaviours as risk factors for overweight in adolescence. Archives of Pediatric and Adolescent Medicine. 158, 385-390

Roberts, S.B., Savage, J., Coward, W.A., Chew, B. and Lucas, A. (1988). Energy expenditure and intake in infants born to lean and overweight mothers. New England Journal of Medicine. 318, 461-466

Reilly, J.J., Methven, E., Mcdowell, C., Hacking, B., Alexander, D., Stewart, L. and Keelnar, C.J.H. (2003). Health consequences of obesity. Archives of Disease in Childhood. 88, 748-752

Rand, C. and Stunkard, A.J. (1978). Obesity and psychoanalysis. Am J Psychiatry, (135), pp. 547551.

Renie, K.L. and Jebb, S.A., 2005. National prevalence of obesity: prevalence of obesity in Great Britain. Obes Rev. 6, 11-12

Renie, K.L. and Jebb, S.A. (2005). National prevalence of obesity: prevalence of obesity in Great Britain. Obes Rev. 6, 11-12

Rand, C. and Stunkard, A.J. (1978). Obesity and psychoanalysis. Am J Psychiatry. 135, 547-551

Steptoe, A., Kunz-Ebrecht, S.R., Brydon, L. and Wardle, J. (2004). Central adiposity and cortisol responses to waking in middle-aged men and women. Int J ObesRelatMetabDisord. 28, 11681173

Wardle, J. and Cooke, L. (2005). The impact of obesity on psychological well-being. Best Practice \& Research Clinical Endocrinology \& Metabolism. $19,421-424$

Wardle, J., Guthrie, C., Sanderson, S., Birch, L. and Plomin, R. (2001). Food and activity preferences in children of lean and obese parents. International Journal of Obesity. 25, 971-977

Williamson, D.F., Madans, J., Anda, R.F., Kleiman, J.C., Kahn, H.S. and Buyers, T. (1993). Recreational physical activity and ten-year weight change in a US national cohort. International Journal of Obesity. 17, 279-286

Webber, L., Hill, C., Saxton, J., Van Jaarsveld, C. H. M. and Wardle, J. (2009). Eating behaviour and weight in children. International Journal of Obesity. $33,21-28$

World Health Organization, (2003). Diet, nutrition and the prevention of chronic diseases. WHO Technical report series, 911. Geneva, WHO
Wadden, T.A. and Stunkard, A.J. (2002). Handbook of Obesity Treatment. New York, NY: The Guilford Press

Yacono-Freeman, L.M. and Gil, K.M. (2004). Daily stress, coping and dietary restraint in binge eating. Int J Eating Diosrd. 36, 204-212 


\section{Supplementary Materials}

\section{Index 1: Child Eating Behaviour Questionnaire (CEBQ)}

Please read the following statements and tick the boxes most appropriate to your child's eating behaviour.

\begin{tabular}{|c|c|c|c|c|c|}
\hline Question & Never & Rarely & $\begin{array}{l}\text { Some } \\
\text { times }\end{array}$ & Often & Always \\
\hline 1. My child loves food & $\square$ & $\square$ & $\square$ & $\square$ & $\square$ \\
\hline 2. My child eats more when worried & $\square$ & $\square$ & $\square$ & $\square$ & $\square$ \\
\hline 3. My child has a big appetite & $\square$ & $\square$ & $\square$ & $\square$ & $\square$ \\
\hline 4. My child finishes his/her meal quickly & $\square$ & $\square$ & $\square$ & $\square$ & $\square$ \\
\hline 5. My child is interested in food & $\square$ & $\square$ & $\square$ & $\square$ & $\square$ \\
\hline 6. My child is always asking for a drink & $\square$ & $\square$ & $\square$ & $\square$ & $\square$ \\
\hline 7. My child refuses new foods at first & $\square$ & $\square$ & $\square$ & $\square$ & $\square$ \\
\hline 8. My child eats slowly & $\square$ & $\square$ & $\square$ & $\square$ & $\square$ \\
\hline 9. My child eats less when angry & $\square$ & $\square$ & $\square$ & $\square$ & $\square$ \\
\hline 10. My child enjoys tasting new foods & $\square$ & $\square$ & $\square$ & $\square$ & $\square$ \\
\hline 11. My child eats less when $\mathrm{s} / \mathrm{he}$ is tired & $\square$ & $\square$ & $\square$ & $\square$ & $\square$ \\
\hline 12. My child is always asking for food & $\square$ & $\square$ & $\square$ & $\square$ & $\square$ \\
\hline 13. My child eats more when annoyed & $\square$ & $\square$ & $\square$ & $\square$ & $\square$ \\
\hline 14. If allowed to, my child would eat too much & $\square$ & $\square$ & $\square$ & $\square$ & $\square$ \\
\hline 15. My child eats more when anxious & $\square$ & $\square$ & $\square$ & $\square$ & $\square$ \\
\hline 16. My child enjoys a wide variety of foods & $\square$ & $\square$ & $\square$ & $\square$ & $\square$ \\
\hline $\begin{array}{l}\text { 17. My child leaves food on his/her plate at the end } \\
\text { of a meal }\end{array}$ & $\square$ & $\square$ & $\square$ & $\square$ & $\square$ \\
\hline $\begin{array}{l}\text { 18. My child takes more than } 30 \text { minutes to finish a } \\
\text { meal }\end{array}$ & $\square$ & $\square$ & $\square$ & $\square$ & $\square$ \\
\hline 19. My child undertakes physical exercise & $\square$ & $\square$ & $\square$ & $\square$ & $\square$ \\
\hline $\begin{array}{l}\text { 20. Given the choice, my child would eat most of the } \\
\text { time }\end{array}$ & $\square$ & $\square$ & $\square$ & $\square$ & $\square$ \\
\hline 21. My child looks forward to mealtimes & $\square$ & $\square$ & $\square$ & $\square$ & $\square$ \\
\hline 22. My child gets full before his/her meal is finished & $\square$ & $\square$ & $\square$ & $\square$ & $\square$ \\
\hline 23. My child enjoys eating & $\square$ & $\square$ & $\square$ & $\square$ & $\square$ \\
\hline 24. My child eats more when she is happy & $\square$ & $\square$ & $\square$ & $\square$ & $\square$ \\
\hline 25. My child is difficult to please with meals & $\square$ & $\square$ & $\square$ & $\square$ & $\square$ \\
\hline 26. My child eats less when upset & $\square$ & $\square$ & $\square$ & $\square$ & $\square$ \\
\hline 27. My child gets full up easily & $\square$ & $\square$ & $\square$ & $\square$ & $\square$ \\
\hline $\begin{array}{l}\text { 28. My child eats more when s/he has nothing else } \\
\text { to do }\end{array}$ & $\square$ & $\square$ & $\square$ & $\square$ & $\square$ \\
\hline $\begin{array}{l}\text { 29. Even if my child is full up s/he finds room to eat } \\
\text { his/her favourite food }\end{array}$ & $\square$ & $\square$ & $\square$ & $\square$ & $\square$ \\
\hline
\end{tabular}




\begin{tabular}{|l|c|c|c|c|c|}
\hline $\begin{array}{l}\text { 30. If given the chance, my child would drink } \\
\text { continuously throughout the day }\end{array}$ & $\square$ & $\square$ & $\square$ & $\square$ \\
\hline $\begin{array}{l}\text { 31. My child cannot eat a meal if s/he has had a } \\
\text { snack just before }\end{array}$ & $\square$ & $\square$ & $\square$ & $\square$ & $\square$ \\
\hline $\begin{array}{l}\text { 32. If given the chance, my child would always be } \\
\text { having a drink }\end{array}$ & $\square$ & $\square$ & $\square$ & $\square$ & $\square$ \\
\hline $\begin{array}{l}\text { 33. My child is interested in tasting food s/he hasn't } \\
\text { tasted before }\end{array}$ & $\square$ & $\square$ & $\square$ & $\square$ & $\square$ \\
\hline $\begin{array}{l}\text { 34. My child decides that s/he doesn't like a food, } \\
\text { even without tasting it }\end{array}$ & $\square$ & $\square$ & $\square$ & $\square$ & $\square$ \\
\hline $\begin{array}{l}\text { 35. If given the chance, my child would always have } \\
\text { food in his/her mouth }\end{array}$ & $\square$ & $\square$ & $\square$ & $\square$ & $\square$ \\
\hline $\begin{array}{l}\text { 36. My child eats more and more slowly during the } \\
\text { course of a meal }\end{array}$ & $\square$ & $\square$ & $\square$ & $\square$ & $\square$ \\
\hline
\end{tabular}

